\title{
A rapid microagglutination test for the diagnosis of Legionella pneumophila (serogroup 1) infection
}

\author{
TG HARRISON, AG TAYLOR \\ From the Division of Microbiological Reagents \& Quality Control, Central Public Health Laboratory, 175 \\ Colindale Avenue, London NW9 5 HT
}

SUMMARY A rapid microagglutination test has been developed which can be performed in 30 minutes. Ninety-seven percent of 96 patients diagnosed as having Legionella pneumophila (serogroup 1) infection by indirect immunofluorescence were also detected by the rapid microagglutination test.

The indirect fluorescent antibody test (IFAT) is the most widely used laboratory method for the detection of antibodies to Legionella pneumophila in the diagnosis of Legionnaires' disease (LD). Although this test has been shown to be reliable ${ }^{1}$ it requires specialised equipment and experienced staff. In an attempt to provide simpler alternatives, tests such as microagglutination $^{2}$ and indirect haemagglutination ${ }^{3}$ have been developed.

The microagglutination test has been employed for studies of antibody levels in large populations ${ }^{4}$ because of the ease of testing large numbers of specimens, but it requires an overnight incubation and results are therefore not obtained rapidly. To reduce the incubation time an adaptation of the microagglutination test has been developed and this study was made to compare its performance against that of the IFAT currently in use in this laboratory. Only serogroup 1 infections have been investigated as disease is most commonly produced by this serogroup in the UK.

\section{Material and methods}

\section{ANTIGENS}

The Rapid Microagglutination Test (RMAT) antigen was prepared from a representative serogroup 1 strain of L pneumophila (Knoxville-1) cultured on enriched blood agar ${ }^{5}$ at $37^{\circ} \mathrm{C}$ in a candle jar for $72 \mathrm{~h}$. The growth of flagellate bacilli was washed off as a dense suspension in $2 \%$ formol buffered saline $\mathrm{pH}$ 7.0 incubated at $37^{\circ} \mathrm{C}$ overnight. This stock antigen was diluted in $0 \cdot 1 M$ Dulbecco A phosphatebuffered saline (PBS) $\mathrm{pH} 6.4$ to give an optical density equivalent to $E_{605}^{1 \mathrm{~cm}} 3 \cdot 0$ (Pye Unicam SP600 spectrophotometer). To this was added an equal volume of PBS pH 6.4 containing $0.005 \%$ safranin; the mixture was left at room temperature for one hour with occasional shaking and then centrifuged at $3000 \mathrm{~g}$ in $50 \mathrm{ml}$ conical centrifuge tubes for $15 \mathrm{~min}$. The supernatant was removed and the remaining pellet resuspended in the same volume of fresh PBS, pH 6.4 (final $E_{605}^{1 \mathrm{~cm}}$ equivalent to 1.5 ). This antigen which was used undiluted for the RMAT, is stable at $4^{\circ} \mathrm{C}$ for at least 4 months.

The antigen used for the IFAT was a formalised yolk-sac antigen (FYSA) prepared from the Pontiac-1 strain of $L$ pneumophila (serogroup 1) as previously described. ${ }^{1}$

\section{SERUM SPECIMENS}

Control subjects

Convalescent sera from 247 patients $(82 \%$ with reported lower respiratory tract illness) submitted to the Division of Microbiological Reagents and Quality Control between February and August 1981, for routine LD serology and found negative (titre $<16$ ) by the IFAT, together with sera from 500 healthy blood donors were tested by the RMAT to give an indication of the detectable antibody levels in patients without $L D$ and in normal healthy subjects.

In addition sera from patients with evidence of other respiratory infections or leptospirosis were tested by RMAT for the presence of cross-reacting antibodies; 37 specimens from 25 patients with Mycoplasma pneumoniae infection, 10 convalescent specimens from 10 patients with Chlamydia psittaci infection, 11 convalescent specimens from 11 patients with Coxiella burnetti infection and 32 specimens from 28 patients with Leptospira spp infection. 
Patients with Legionnaires' disease

The antibody levels in 170 sera from 96 patients diagnosed as having LD (-that is, a four-fold or greater rise in paired sera to a titre of at least 64 , or a single titre of 128 with a relevant clinical history), submitted to this Division between January and December 1980, were measured by the RMAT and the IFAT.

\section{RMAT METHOD}

To each well of a V-bottomed microtitre plate $25 \mu \mathrm{l}$ of PBS pH 6.4 was added, $25 \mu \mathrm{l}$ of the serum sample was then added to the first well of each row and doubling dilutions were made. Antigen $(25 \mu \mathrm{l})$ was added to each well, the plates were then sealed with clear plastic plate sealers and shaken for $10 \mathrm{~s}$ (Dynatech Microshaker). The plates were incubated for $10 \mathrm{~min}$ at room temperature, and then centrifuged in Microtitre plate carriers for $4 \mathrm{~min}$ at $\mathbf{3 0 0}$ $g$ (1000 rpm, MSE, GF-8 centrifuge). The sealers were removed, and the plates inclined at an angle of $70^{\circ}$ and left for $10 \mathrm{~min}$ before reading.

\section{Reading the RMAT}

A negative result is seen as a button of stained bacteria which has streaked down the side of the well giving a "tear-drop" pattern (Figure, row B). A positive result is usually seen as a tight button with no streaking (Figure, row A), but a small number of strongly positive specimens sometimes fail to give a tight button and remain diffuse (Figure, row $\mathrm{C}$ ), however both patterns are easily distinguishable from the negative tear-drop pattern. The titre is expressed as the reciprocal of the highest serum dilution (before addition of the antigen) giving a positive result.

\section{IFAT METHOD}

The IFAT has been described in full elsewhere. ${ }^{1}$

\section{POSITIVE CONTROL SERA}

To ensure that the RMAT and IFAT were each giving reproducible results the same positive reference human serum was titrated on each occasion. This serum consistently gave a titre of 64 in the RMAT and 128 in the IFAT.

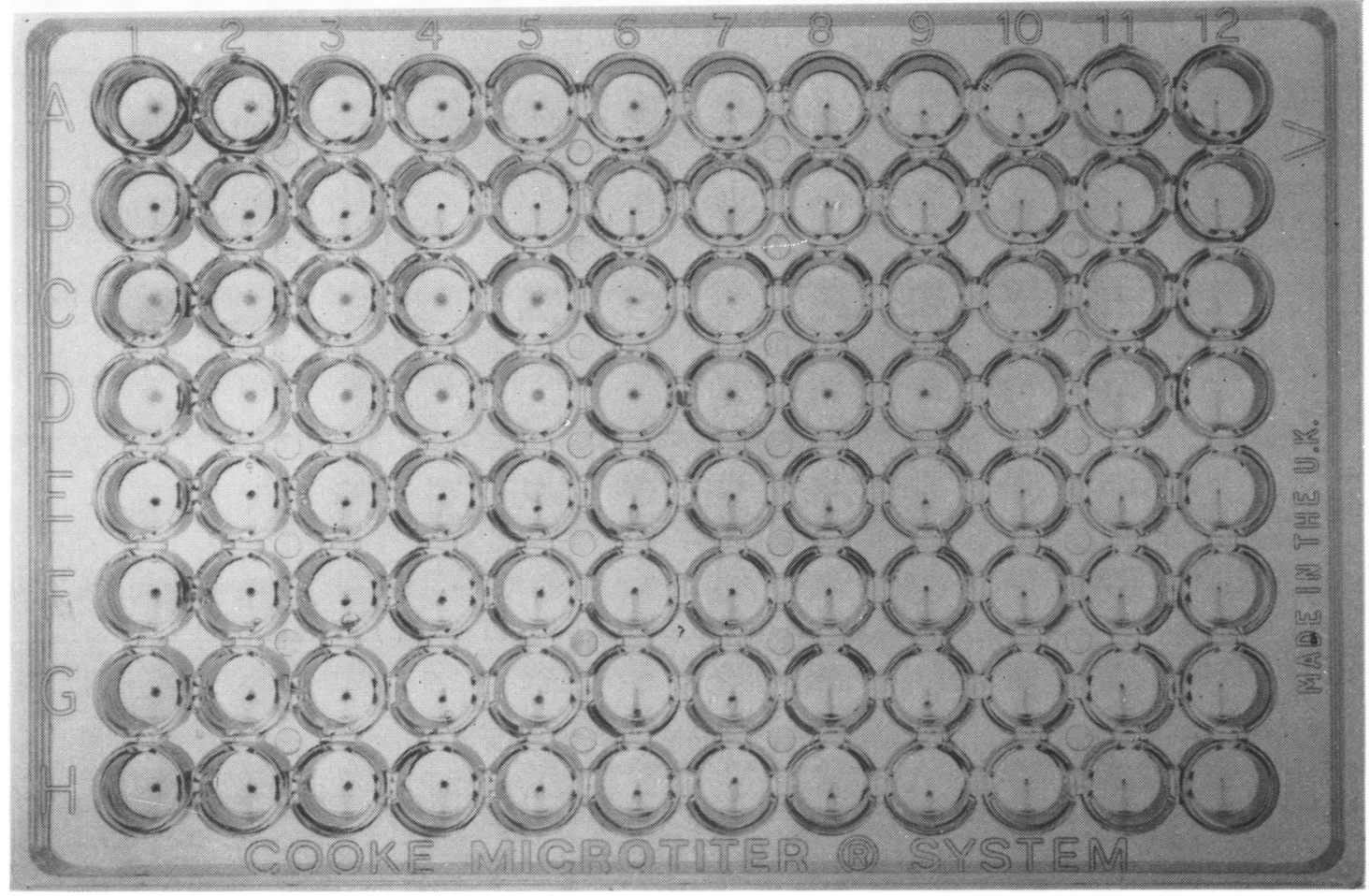

Reading the RMAT-row $A$ is the reference positive control, wells $1-6$ show a positive reaction. Well 7-12 show a negative reaction (titre $=64$ ); row $B$ is a negative serum (titre $<2$ ); row $C$, wells $8-11$ show the diffuse result sometimes seen with a strongly positive serum. (titre $=2048$ ) 


\section{Results}

\section{CONTROL SUBJECTS}

Detectable antibody levels in sera from the 500 blood donors as estimated by the RMAT are shown in Table $1,1.6 \%$ gave titres of $\geqslant 8$. Of the 247 sera submitted for routine LD serology which were negative $(<16)$ by IFAT, $4.4 \%$ gave titre of $\geqslant 8$ (Table 2).

No titres $\geqslant 8$ were obtained on sera from patients with respiratory infections other than LD (Table 3). A positive titre of 16 was, however, seen in one of the 28 patients with leptospirosis.

On the basis of these control results a titre of $\geqslant 8$ in the RMAT was considered positive and a titre of $<8$ seronegative for $\mathrm{LD}$.

Table 1 Titres obtained by the RMAT in sera from 500 blood donors

\begin{tabular}{lllllll}
\hline & \multicolumn{3}{l}{ Titre } & & & \\
\cline { 2 - 7 } & $<2$ & 2 & 4 & 8 & 16 & $>16$ \\
\hline No of donors & 461 & 19 & 12 & 4 & 4 & 0 \\
Percentage donors & $92 \cdot 2 \%$ & $3.8 \%$ & $2 \cdot 4 \%$ & $0.8 \%$ & $0.8 \%$ & $0.0 \%$ \\
\hline
\end{tabular}

\section{LD PATIENTS}

Using the above criteria $93 / 96$ patients $(97 \%$ ) diagnosed as LD by IFAT (Table 4) were also positive by RMAT, and $89 / 93$ of these gave titre $\geqslant 16$.

One of the three patients who was seronegative had a titre of 256 in a single specimen by the IFAT and gave a RMAT titre of 4 . The other two patients gave fourfold rises in the IFAT, and gave a twofold rise ( $<2$ to 4$)$ and a standing titre ( 2$)$ respectively by the RMAT.

If the results of the two tests on the 170 sera from the 96 patients are compared they give $91 \%$ agreement (percentage of sera positive by both tests plus percentage of sera negative by both tests). Ten specimens $(6 \%)$ were positive $(\geqslant 16)$ in the IFAT and negative $(<8)$ in the RMAT and 5 specimens $(3 \%)$ were negative $(<16)$ in the IFAT and positive $(\geqslant 8)$ in the RMAT.

\section{Discussion}

The RMAT is simple to perform and specimens are processed and results obtained in 30 min whereas $16 \mathrm{~h}$ are required for the previously described microagglutination test. ${ }^{2}$ If a titre of $\geqslant 8$ is considered posi-

Table 2 Titres obtained by the RMAT in sera from 247 patients with IFAT titre $<16$

\begin{tabular}{|c|c|c|c|c|c|c|c|}
\hline \multirow[t]{2}{*}{ Reported illness } & \multicolumn{7}{|l|}{ Titre } \\
\hline & $<2$ & 2 & 4 & 8 & 16 & 32 & Totals \\
\hline $\begin{array}{l}\text { Pneumonia } \\
\text { Chest infection } \\
\text { Pyrexia of unknown origin } \\
\text { Others and not stated } \\
\text { Totals }\end{array}$ & $\begin{array}{c}156 \\
13 \\
12 \\
25 \\
206 \\
(83 \cdot 4 \%)\end{array}$ & $\begin{array}{c}12 \\
2 \\
1 \\
3 \\
18 \\
(7 \cdot 3 \%)\end{array}$ & $\begin{array}{l}6 \\
2 \\
1 \\
3 \\
12 \\
(4 \cdot 9 \%)\end{array}$ & $\begin{array}{l}4 \\
3 \\
- \\
-7 \\
(2 \cdot 8 \%)\end{array}$ & $\begin{array}{l}\frac{2}{-} \\
1 \\
3 \\
(1 \cdot 2 \%)\end{array}$ & $\begin{array}{l}\frac{1}{-} \\
- \\
(0 \cdot 4 \%)\end{array}$ & $\begin{array}{c}181 \\
20 \\
14 \\
32 \\
247 \\
(100 \%)\end{array}$ \\
\hline
\end{tabular}

Table 3 Titres obtained by the RMAT in sera from patients with respiratory illness or leptospirosis (number of patients in parentheses)

\begin{tabular}{|c|c|c|c|c|c|c|c|}
\hline & \multicolumn{6}{|l|}{ Titre } & \multirow[t]{2}{*}{ Totals } \\
\hline & $<2$ & 2 & 4 & 8 & 16 & $>16$ & \\
\hline $\begin{array}{l}\text { Mycoplasma pneumoniae } \\
\text { Chlamydia psittaci } \\
\text { Coxiella burnetti } \\
\text { Leptospira sp } \\
\end{array}$ & $\begin{array}{r}25 \\
8 \\
9 \\
25 \\
\end{array}$ & $\begin{array}{l}10^{*} \\
2 \\
2 \\
5\end{array}$ & $\frac{2+}{1}$ & $\begin{array}{l}E \\
=\end{array}$ & $\frac{-}{1}$ & $\begin{array}{l}- \\
-\end{array}$ & $\begin{array}{l}37(25) \\
10(10) \\
11(11) \\
32(28)\end{array}$ \\
\hline
\end{tabular}

*Five patients had standing titres of 2.

tOne patient had a standing titre of 4 .

Table 4 Comparison of IFAT and RMAT results from 96 patients with $L D$

\begin{tabular}{|c|c|c|c|c|}
\hline \multirow[t]{2}{*}{ IFAT results } & \multicolumn{4}{|l|}{$R M A T$} \\
\hline & $\begin{array}{l}\text { Fourfold rise in titre to } \\
\geqslant 8\end{array}$ & $\begin{array}{l}\text { Standing titre } \\
\geqslant 8\end{array}$ & $\begin{array}{l}\text { Single titre } \\
\geqslant 8\end{array}$ & $\begin{array}{l}\text { Negative } \\
<8\end{array}$ \\
\hline $\begin{array}{l}\text { Fourfold rise in titre to } \geqslant 64 \\
\text { Standing titre } \geqslant 128 \\
\text { Single titre } \geqslant 128\end{array}$ & $\begin{array}{r}53 \\
0 \\
0\end{array}$ & $\begin{array}{l}6 \\
8 \\
0\end{array}$ & $\begin{array}{r}0 \\
0 \\
26\end{array}$ & $\begin{array}{l}2 \\
0 \\
1\end{array}$ \\
\hline
\end{tabular}


tive the RMAT clearly differentiates between infected and control populations; $97 \%$ of LD patients positive as determined by IFAT, were also positive by RMAT whereas $>95 \%$ of a control non-LD population gave negative results by RMAT. In contrast to the microagglutination test $^{2}$ the RMAT does not appear to be less sensitive than the IFAT and titres obtained by both RMAT and IFAT were broadly similar.

It has been shown that the microagglutination test predominantly detects $\operatorname{IgM}^{7}$ while the conjugate used in the IFAT detects both IgM and IgG, also different strains of $L$ pneumophila were used to prepare the two antigens, and these differences may account for some of the disagreement in results in the two tests. In one of the three patients who was seronegative by RMAT the specimen had been taken two months after the onset of symptoms and IFAT examination with immunoglobulin class specific conjugates revealed that the antibody was predominantly IgG with very little detectable IgM.

It has been suggested that crossreacting antibodies between Mycoplasma pneumoniae and $L$ pneumophila may occur in the IFAT, ${ }^{8}$ however several authors have been unable to confirm this, although evidence has been presented suggesting that concomitant infections by both organisms may be involved. ${ }^{9}$ A small number of selected sera from patients with respiratory illnesses have been investigated for evidence of cross-reactions in the RMAT. No positive titre were seen in these patients with Mycoplasma pneumoniae, Chlamydia psittaci or Coxiella burnetti infection.

It has been reported that leptospirosis has been misdiagnosed as $\mathrm{LD}^{10}$ by a fourfold rise in antibody levels in the IFAT; however we have been unable to demonstrate cross-reacting antibody using FYSA (serogroup 1) in over 40 cases of leptospirosis (unpublished data). Other authors have shown high titres of antibodies against $L$ pneumophila in a patient with leptospirosis but concluded that this either indicated concomitant infection or exposure to the two organisms ${ }^{11}$ which are ecologically related. Of the 28 patients with leptospirosis investigated here only one gave a positive titre by RMAT, and this patient gave a negative titre by IFAT.

In conclusion, a rapid, and simple test which requires little specialised equipment is described which can discriminate between the diseased and non-diseased populations, and gives good agreement with the IFAT. It would be suitable for large population studies or as a diagnostic screening test particularly by laboratories which do not have suitable facilities to undertake the IFAT. It would seem advisable that all RMAT-positive specimens should also be tested by IFAT, and in the absence of isolation of, or demonstration of the causative organism to regard with caution any of these that are IFATnegative.

We thank Mr PZ Mochnaty for technical advice and Dr TD Davies of the North London Transfusion Centre for sera from blood donors. We are grateful to Dr PS Gardner and Dr CSF Easmon for helpful advice, and to others who have sent us serum specimens.

\section{References}

' Harrison TG, Taylor AG. Diagnosis of Legionella pneumophila infection by means of formolised yolk-sac antigens. J Clin Pathol 1982;35:211-4.

${ }^{2}$ Farshy CE, Klein GC, Feeley JC. Detection of antibodies to Legionnaires' disease organism by microagglutination and micro-enzyme-linked immunosorbent assay tests. $J$ Clin Microbiol 1978;7:327-31.

${ }^{3}$ Edson DC, Steifel HE, Wentworth BB, Wilson L. Prevalence of antibodies to Legionnaires' disease: A seroepidemiologic survey of Michigan residents using the haemagglutination test. Ann Intern Med 1979;90:691-3.

4 Smalley DL, Ourth DD. Seroepidemiology of Legionella pneumophila. A study of adults from Memphis, Tennessee, USA. Am J Clin Pathol 1981;75:201-3.

${ }^{s}$ Greaves PW. New methods for isolation of Legionella pneumophila. J Clin Pathol 1980;33:581-4.

- Blackmon JA, Chandler FW, Cherry WB, et al, Legionellosis. Am J Pathol 1981;3:429-65.

' Farshy CE, Cruce DD, Klein GC, Wilkinson HW, Feeley JC. Immunoglobulin specificity of the microagglutination test for the Legionnaires' disease bacterium. Ann Intern Med 1979;90:690.

${ }^{8}$ Grady GF, Gilfillan RF. Relation of Mycoplasma pneumoniae seroreactivity, immuno-suppression and chronic disease to Legionnaires' disease. Ann Intern Med 1979;90:607-10.

${ }^{9}$ Taylor AG, Harrison TG, Andrews BE, Sillis M. Serological differentiation of Legionnaires' disease and Mycoplasma pneumoniae pneumonia. Lancet 1980;i:764.

${ }^{10}$ Tsai TF, Fraser DW. The diagnosis of Legionnaires' disease (editorial). Ann Intern Med 1978;89:413-4.

"Dournon E, Bercovier H. Maladie des Legionnaires et Leptospiroses: parentés épidémiologiques ou antigéniques? Med Mal Infect 1980;10:418-21.

Requests for reprints to: Mr TG Harrison, Division of Microbiological Reagents and Quality Control, Central Public Health Laboratory, 175 Colindale Avenue, London NW9 5HT, England. 